\title{
Exophenotypic effects of chromosomal change: the case of Leptysma argentina (Orthoptera)
}

\author{
P. C. COLOMBO* \\ Laboratorio de Genética, Departamento de Ciencias Biológicas, Facultad de Ciencias Exactas y Naturales, \\ Universidad de Buenos Aires, Intendente Güiraldes y Costanera Norte, (1428) Buenos Aires, Argentina
}

\begin{abstract}
Most of the literature about phenotypic effects of chromosomal change has dealt with its effects on chiasma frequency and/or distribution, whereas whether or not they affect the exophenotype has received less attention and has remained controversial. In the present paper morphometrical variables of the species Leptysma argentina were analysed in connection with chromosome polymorphisms for a centric fusion and a supernumerary segment.

The centric fusion between pairs 3 and 6 (fusion 3/6) and a supernumerary segment in the smallest pair of the complement $\left(s_{1}\right)$ were consistently proved to have effects on chiasma frequency and position; preliminary analyses had shown, however, that fusion $3 / 6$ could be correlated with some effects on body size (Colombo, 1989). In the present paper the analysis of femur, tibia, prothorax and total length as well as prothorax height on larger samples were consistent in showing that both polymorphisms are positively correlated with increasing total length; in the case of the supernumerary segment, however, this effect is not constant over all the populations sampled.

An adaptive change in body size may be achieved through selection on: (i) genetic factors that affect this trait; or (ii) chromosome polymorphisms with exophenotypic effects. This latter case would be more effective, because genetic factors are usually polygenic and hence their response to selection would be slow. It is tempting to say that this could be the case for L. argentina, because in grasshoppers increased body size can be related to tolerance to cold or dry environments.
\end{abstract}

Keywords: centric fusions, chromosome polymorphisms, morphometrical variables, Orthoptera, supernumerary segments.

\section{Introduction}

Most of the studies about phenotypic effects of chromosomal change in Orthoptera have traditionally dealt with changes in chiasma conditions, which have been extensively studied (see John, 1983 for a revision). However, comparatively little literature has been devoted to exophenotypic effects of chromosome rearrangements (see White, 1973 for a review), at least when compared with the growing amount of research in Drosophila (Partridge et al., 1987; Santos et al., 1988, 1992; Norry et al., 1995). This may be because Orthopterans are especially amenable to chiasma studies owing to their very

*Correspondence. E-mail: colombop@biolo.bg.fcen.uba.ar. clear meiotic figures, whereas morphometric studies are time-consuming and usually not very rewarding. In fact, no evidence of chromosome rearrangements causing exophenotypic effects per se had been found in grasshoppers (Groeters \& Shaw, 1992) until very recently (Colombo, 1989; Remis, 1991). The absence of evidence has led some authors to exclude the possibility of exophenotypic effects (Lande, 1979) or to favour recombination effects (John, 1983) of chromosome rearrangements in their chromosome evolution models.

However, the presence of exophenotypic variations resulting from chromosome rearrangements may be concealed by the fact that many of the rearrangements under study were polytypic; obviously, little can be said of two different populations 
which are genetically, as well as chromosomally, divergent. On the other hand, there are cases of sibling species that can only be told apart through the study of their karyotype (Patterson \& Stone, 1952; Reig et al., 1980). The study of organisms that contain different karyotypes in the same population (in polymorphic conditions) perhaps offers the most plausible route to resolving this problem.

Leptysma argentina is a South American species which contains populations that are polymorphic for a centric fusion between pairs 3 and 6 (fusion 3/6) and also for a supernumerary segment $\left(\mathrm{s}_{1}\right)$. Both rearrangements showed consistent effects on chiasma frequency and/or distribution (Colombo, 1992, 1993a), and preliminary analyses established that the posession of fusion $3 / 6$ is positively correlated with increased body size (Colombo, 1989). Larger populational samples were analysed in this study in order to corroborate this finding.

\section{Materials and methods}

The morphometrical study was carried out on dissected individuals from nine populations, detailed in Table 1, whose chromosomal study is described elsewhere (Colombo, 1989, 1993b,c). Measures were obtained with the aid of a graded binocular microscope. The following variables were examined:

1 tegmina length; in some cases this trait was impossible to measure because tegminae were worn out on their free side (only one tegmina per individual was measured);
2 total length; it was assessed from the phastigium to the articulation between femur and tibia; this measure is better than that between the phastigium and the rear extreme of the abdomen, because its length may vary according to the hydration of the grasshopper (R. Ronderos, personal communication);

3 femur length (only one femur per individual was measured);

4 tibia length (only one tibia per individual was measured);

5 prothorax length;

6 prothorax height.

Individuals were captured manually and subsequently dissected in the field; their testes were fixed in 3:1 ethanol:acetic acid fixative and subsequently stored at $4^{\circ} \mathrm{C}$. Slides were made by squashing testicular follicles in lactoproprionic orcein, and karyotypes were observed in metaphase I. A minimum of five cells per individual were examined prior to the determination of the karyotype.

\section{Results}

\section{Intrapopulational studies}

In the present paper the samples taken from Yarará Guazú (YG), El Palmar (EP) and Los Loros (LL), were assessed separately over 3-4 years (1986-90), unlike previous studies. In Table 2 one of the variables, mean total body length, is shown for EP and YG populations in all three karyotypes (FF, UF and

Table 1 Provenance, sample size and approximate date of collection of the Leptysma argentina populations here analysed

\begin{tabular}{lcl}
\hline Locality & Number of males collected & Collection date \\
\hline Zárate (Z) & 16 & Sept. 1984 \\
Isla Talavera (IT) & 10 & Dec. 1985 \\
Puerto Talavera (PT) & 67 & Oct.-Nov. 1985 \\
Pilar (P) & 13 & Sept. 1985 \\
Río Luján (RL) & 50 & Dec. 1985 \\
& 48 & Oct.-Nov.Dec. 1985 \\
Arroyo de los Loros (LL) & 20 & Dec. 1985 \\
Yarará Guazú (YG) & 25 & Dec. 1986 \\
& 18 & Dec. 1988 \\
Arroyo El Palmar (EP) & 74 & Oct.-Dec. 1990 \\
& 32 & Dec. 1985 \\
& 22 & Dec. 1986 \\
Santa Fe (SF) & 17 & Dec. 1987 \\
\hline
\end{tabular}


UU; F stands for 'fused' and U for 'unfused') over the years 1986, 1987, 1988 and 1990. Several trends are apparent.

1 FF individuals are always larger than UU ones; the effect is statistically significant and constant over all the six categories here analysed.

2 Overall mean total length may change abruptly and significantly from one generation to the next, perhaps reflecting environmental fluctuations (this is the case of YG and EP in 1988) and these fluctuations between years can be significant (Table 2).
3 It had been stated previously that the effect of the fusion on total length showed a dosage effect; however, the analysis of more and larger samples shows that this pattern is by no means a regular feature of fusion 3/6. It applies to EP 1987 and YG 1988, but UF individuals may be either smaller than UU ones (EP 1986, 1988) or not significantly different from UU (YG 1986) or FF (YG 1990) individuals (Table 2).

4 Segment $s_{1}$ was reported as neutral with respect to the total length effect; this is true in most of the populations so far analysed. However, in this study it

Table 2 Mean body size per fusion 3/6 karyomorph in populations El Palmar (EP) and Yarará Guazú (YG) of Leptysma argentina in years 1986-90

(a) Frequencies

\begin{tabular}{|c|c|c|c|c|}
\hline & & Year of & collection & \\
\hline & 1986 & 1987 & 1988 & 1990 \\
\hline El Palmar & & & & \\
\hline UU & $24.88 \pm 0.19(8)$ & $24.33 \pm 0.34(7)$ & $25.72 \pm 0.28(8)$ & - \\
\hline UF & $24.63 \pm 0.25(16)$ & $25.18 \pm 0.35(7)$ & $25.31 \pm 0.30(12)$ & - \\
\hline FF & $25.50 \pm 0.37(7)$ & $26.20 \pm 0.73(2)$ & $26.27 \pm 0.46(4)$ & - \\
\hline Average & $24.93(31)$ & $24.94(16)$ & $25.64(24)$ & - \\
\hline Yarará $G u$ & Łazú & & & \\
\hline UU & $24.29 \pm 0.19(17)$ & - & $24.40 \pm 0.21(7)$ & $24.90 \pm 0.17(16)$ \\
\hline UF & $25.25 \pm 0.28(16)$ & - & $25.08 \pm 0.27(9)$ & $24.87 \pm 0.14(42)$ \\
\hline $\mathrm{FF}$ & $25.28 \pm 0.31(7)$ & - & $25.38 \pm 0.48(3)$ & $25.43 \pm 0.23(16)$ \\
\hline Average & $24.98(31)$ & - & $25.98(19)$ & $25.00(74)$ \\
\hline
\end{tabular}

(b) ANOVA

\begin{tabular}{lrrcrl}
\hline Source & d.f. & \multicolumn{1}{c}{ SS } & MS & VR & $P$ \\
\hline El Palmar & & & & & \\
Between & 8 & 8.3433 & 1.4287 & 2.118 & $0.20 \mathrm{NS}$ \\
A-karyotype & 2 & 5.8841 & 2.1151 & 14.017 & $0.015^{*}$ \\
B-years & 2 & 1.5230 & 2.6107 & 3.871 & $0.025^{*}$ \\
A $\times$ B & 4 & 0.9360 & 0.1509 & 0.224 & $0.92 \mathrm{NS}$ \\
Within & 68 & 49.7284 & 0.6745 & - & \\
Total & 70 & 35.4725 & - & - & \\
Yarará Guazú & & & & & \\
Between & 8 & 11.5389 & 1.4423 & 1.882 & $0.069 \mathrm{NS}$ \\
A-karyotype & 2 & 6.3780 & 3.189 & 9.125 & $0.032^{*}$ \\
B-years & 2 & 4.0894 & 2.0447 & 2.669 & $0.073 \mathrm{NS}$ \\
A $\times$ B & 4 & 1.0715 & 0.2678 & 0.350 & $0.844 \mathrm{NS}$ \\
Within & 115 & 88.1175 & 0.7662 & - & \\
Total & 123 & 99.6564 & - & - & \\
\hline
\end{tabular}

The number of males measured is given in parentheses. UU, unfused homozygotes; UF, heterozygotes; FF, fusion homozygotes. 
is apparent that $s_{1}$ has a significant effect on total length (Table 3a) as well as prothorax length in EP and YG, the other measures showing the same tendency but at nonsignificant levels; samples had to be pooled because of the low number of $s_{1}$ carriers. A larger sample taken in YG in 1990, in which all six combinations of karyotypes for fusion $3 / 6$ and segment $s_{1}$ were compared (no homozygotes for $s_{1}$ were found) showed the same results (Table $3 b$ ). In this case femur length was also significant for fusion carriers. For the sake of brevity, only the overall total length effect is shown in the tables.

Table 3 Exophenotype effect of fusion $3 / 6$ and segment $s_{1}$ on total length (TL) in samples of Leptysma argentina from YG and EP (1988 and 1990)

(a) (i) Pooled samples of EP and YG (1988)

\begin{tabular}{|c|c|c|c|c|}
\hline \multirow{2}{*}{$\begin{array}{l}\text { Segment } \\
\text { karyotype }\end{array}$} & \multicolumn{3}{|c|}{ Fusion karyotype } & \multirow[b]{2}{*}{ Mean $(n)$} \\
\hline & $\mathrm{UU}(n)$ & $\mathrm{UF}(n)$ & $\mathrm{FF}(n)$ & \\
\hline BB & $24.81 \pm 0.16(8)$ & $25.13 \pm 0.19(18)$ & $25.46 \pm 0.31(4)$ & $25.09(30)$ \\
\hline $\mathrm{Bs}_{1}$ & $25.44 \pm 0.23(7)$ & $25.67 \pm 0.39(3)$ & $26.43 \pm 0.42$ & $25.72(13)$ \\
\hline Mean & $25.10(15)$ & $25.21(21)$ & $25.89(7)$ & 25.79 \\
\hline
\end{tabular}

(ii) ANOVA

\begin{tabular}{lccccc}
\hline Source & d.f. & SS & MS & VR & $P$ \\
\hline Between & 5 & 7.1437 & 1.4287 & 2.118 & 0.082 NS \\
$\mathrm{F}$ & 2 & 4.2301 & 2.1151 & 28.052 & $0.034^{*}$ \\
$\mathrm{~s}_{1}$ & 1 & 2.6107 & 2.6107 & 34.625 & $0.039^{*}$ \\
$\mathrm{~F} \times \mathrm{s}_{1}$ & 2 & 0.1509 & 0.0754 & 0.224 & $0.80 \mathrm{NS}$ \\
Within & 42 & 28.3288 & 0.6745 & - & \\
Total & 47 & 35.4725 & - & - & \\
\hline
\end{tabular}

(b) (i) Sample of YG (1990)

\begin{tabular}{lllll}
\hline & \multicolumn{3}{c}{ Fusion karyotype } \\
\cline { 2 - 4 } $\begin{array}{l}\text { Segment } \\
\text { karyotype }\end{array}$ & \multicolumn{1}{c}{$\mathrm{UU}(n)$} & \multicolumn{1}{c}{$\mathrm{UF}(n)$} & \multicolumn{1}{c}{ FF $(n)$} & Mean $(n)$ \\
\hline BB & $24.81 \pm 0.17(14)$ & $24.97 \pm 0.15(35)$ & $24.95 \pm 0.21(12)$ & $24.93(61)$ \\
Bs $_{1}$ & $25.40 \pm 0.48(2)$ & $25.65 \pm 0.25(7)$ & $25.30 \pm 0.32(4)$ & $25.50(13)$ \\
Mean & $24.88(16)$ & $25.08(42)$ & $25.04(7)$ & $25.03(74)$ \\
\hline
\end{tabular}

(ii) ANOVA

\begin{tabular}{lccccc}
\hline Source & d.f. & SS & MS & VR & $P$ \\
\hline Between & 5 & 7.5405 & 1.1081 & 2.788 & $0.023^{*}$ \\
$\mathrm{~F}$ & 2 & 3.7701 & 1.8851 & 31.210 & $0.03^{*}$ \\
$\mathrm{~s}_{1}$ & 1 & 3.6496 & 3.6496 & 60.424 & $0.016^{*}$ \\
$\mathrm{~F} \times \mathrm{s}_{1}$ & 2 & 0.1208 & 0.0604 & 0.324 & 0.724 NS \\
Within & 68 & 44.0968 & 0.6485 & - & \\
Total & 73 & 51.6373 & - & - & \\
\hline
\end{tabular}




\section{Comparisons between populations: correlation of morphometrical variables with fusion 3/6 frequency}

In the previous study it had been shown that the correlation between fusion $3 / 6$ frequency and mean total length per population, all karyotypes pooled, was highly significant over nine populations from all over the distribution area of $L$. argentina (Fig. 1a). This result was expected because fusion $3 / 6$ increases total length in FF individuals.

In the present study, however, each karyotype was considered individually. Mean morphometrical values for all traits measured are given for all three karyotypes in the seven populations considered (Table 4). Remarkably, when correlations for each karyotype were performed separately they were found to be highly significant as well $\left(b_{\mathrm{UU}}=\right.$ $0.9575 \pm 0.6792 ; b_{\mathrm{UF}}=1.1969 \pm 0.9940 ; b_{\mathrm{FF}}=1.2261 \pm$
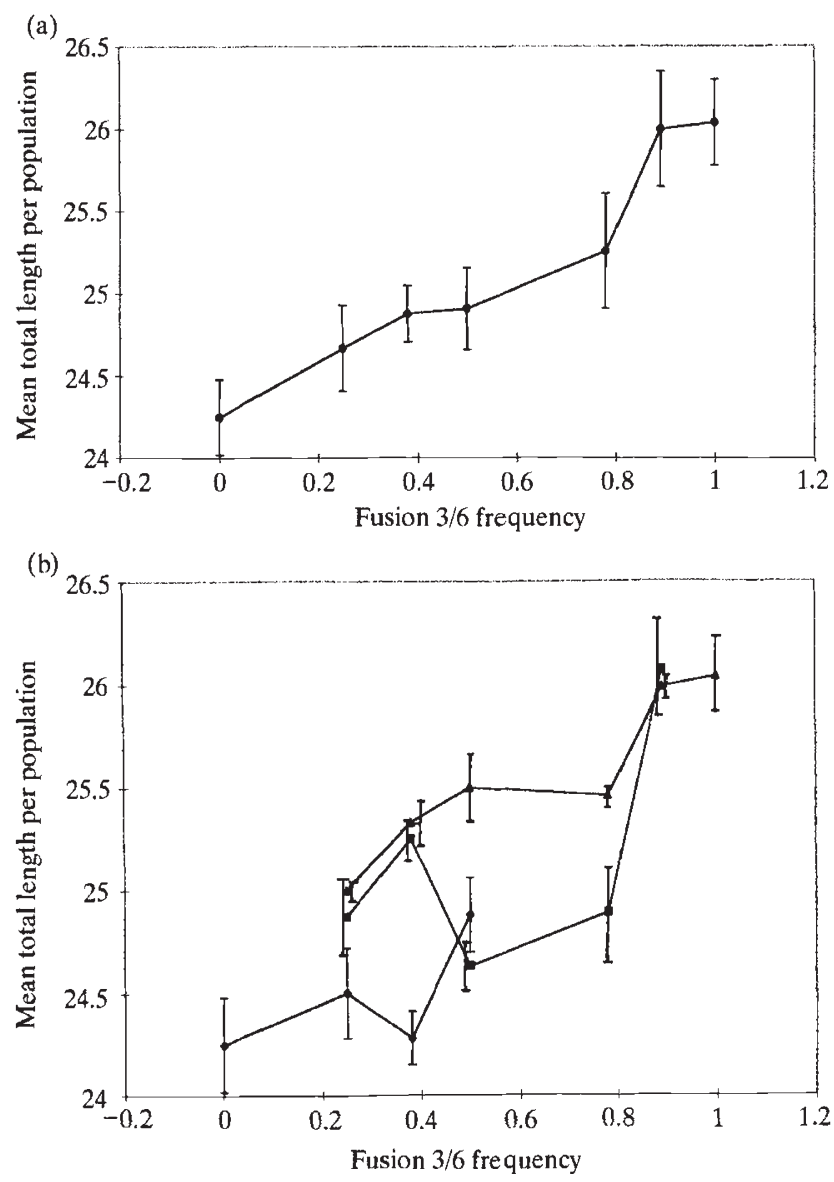

Fig. 1 Mean body size per population of Leptysma argentina plotted against fusion 3/6 frequency for (a) all individuals (karyotypes pooled) and (b) each karyotype separately. $\bullet$, basic homozygotes; $\boldsymbol{\square}$, heterozygotes; $\Delta$, fusion homozygotes.
0.25535; Fig. 1b): this suggests that not all of the correlation between mean total length and fusion $3 / 6$ frequencies is caused by the effect of the fusion. The slopes were not significantly different between karyotypes $(P=0.18)$ but all of them were significantly different from the slope of the pooled karyotypes represented in Fig. 1a $(P=0.014)$, the latter being steeper $(b=1.7534 \pm 0.2372)$ (Figs 1a and $b)$.

\section{Discussion}

The present results show that fusion $3 / 6$ affects the distribution of size-related traits in L.argentina populations, mainly because of an effect of fusion $3 / 6$ on overall total length. This effect was consistent between years and between populations, even though there are variations in overall mean total length over the years. These results are consistent with and extend the results given in Colombo (1989) on the same species; albeit showing that the effect of fusion $3 / 6$ is a real one, it is also demonstrated that the correlation between fusion frequency and mean total length is somehow spurious, because individuals from populations with higher fusion frequencies also tend to be bigger, irrespective of the karyotype.

However, the correlation between the fusion and increased body size does not demonstrate that the exophenotypic effect is a result of the fusion per se. Indeed, because the centric fusion $3 / 6$ precludes interstitial chiasma formation as a result of a stubborn distal localization (Colombo, 1993a), a fused $3 / 6$ submetacentric could contain several genes that are not present in the acrocentrics 3 and 6 . So the cause of an increase of size in fusion carriers could lie in the genetic content, rather than the fusion itself. Given that fusion $3 / 6$ has a greater frequency in areas where this species is bigger, it is tempting to suggest that the fusion originated there, and later expanded further north carrying with it the genes for enhanced body size.

Moreover, an effect of segment $s_{1}$ is also apparent; this effect, however, is less strong and not consistent over the populations. In this case it is clear that it would be a direct effect of the chromosomal change and not of genes carried by it, because supernumerary segments usually carry no genes (John, 1983).

The effect of fusion $3 / 6$ on total length is suggestive in the light of recent evidence coming from Drosophila studies (Ruiz et al., 1991; Norry et al., 1995), where an adaptive inversion with a dose effect on increased body size (Hasson et al., 1992) is correlated both with increased longevity (Hasson et 
Table 4 Mean size per karyotype for every Leptysma argentina population and for all morphometrical variables studied (see Materials and methods). Fusion 3/6 frequency in each population $(q)$ is also shown

\begin{tabular}{|c|c|c|c|c|c|c|c|c|}
\hline \multirow{2}{*}{$\begin{array}{l}\text { Location } \\
(q)\end{array}$} & \multirow[b]{2}{*}{ Karyotype } & \multicolumn{7}{|c|}{ Morphometrical variables } \\
\hline & & $\mathrm{TL}$ & TegL & FL & TibL & PTxL & $\mathrm{PTxH}$ & $n$ \\
\hline \multirow{3}{*}{$\begin{array}{l}\text { SF } \\
(0.0)\end{array}$} & UU & $24.25 \pm 0.23$ & $24.15 \pm 0.36$ & $11.42 \pm 0.13$ & $10.08 \pm 0.12$ & $3.79 \pm 0.05$ & $2.79 \pm 0.03$ & 11 \\
\hline & UF & - & - & - & - & - & - & - \\
\hline & FF & - & - & - & - & - & - & - \\
\hline \multirow{3}{*}{$\begin{array}{l}\mathrm{LL} \\
(0.25)\end{array}$} & UU & $24.50 \pm 0.22$ & $24.94 \pm 0.31$ & $11.75 \pm 0.14$ & $10.18 \pm 0.13$ & $3.89 \pm 0.04$ & $2.79 \pm 0.03$ & 13 \\
\hline & UF & $4.87 \pm 0.26$ & $26.25 \pm 0.38$ & $12.03 \pm 0.16$ & $10.33 \pm 0.28$ & $3.83 \pm 0.05$ & $2.83 \pm 0.04$ & 9 \\
\hline & FF & $25.00 \pm 0.06$ & $25.25 \pm 0.15$ & $11.97 \pm 0.15$ & $10.67 \pm 0.07$ & $3.93 \pm 0.30$ & $2.77 \pm 0.10$ & 2 \\
\hline \multirow{3}{*}{$\begin{array}{l}\text { YG } \\
(0.38)\end{array}$} & UU & $24.28 \pm 0.13$ & $23.63 \pm 0.19$ & $11.82 \pm 0.07$ & $10.22 \pm 0.07$ & $3.77 \pm 0.02$ & $2.85 \pm 0.02$ & 40 \\
\hline & UF & $25.25 \pm 0.11$ & $24.55 \pm 0.17$ & $11.97 \pm 0.08$ & $10.56 \pm 0.07$ & $3.94 \pm 0.02$ & $2.77 \pm 0.01$ & 67 \\
\hline & FF & $25.33 \pm 0.17$ & $25.33 \pm 0.26$ & $12.33 \pm 0.13$ & $10.83 \pm 0.11$ & $3.93 \pm 0.03$ & $2.77 \pm 0.02$ & 26 \\
\hline \multirow{3}{*}{$\begin{array}{l}\text { EP } \\
(0.50)\end{array}$} & UU & $24.88 \pm 0.18$ & $25.00 \pm 0.23$ & $11.88 \pm 0.10$ & $10.19 \pm 0.09$ & $3.83 \pm 0.03$ & $2.81 \pm 0.03$ & 23 \\
\hline & UF & $24.63 \pm 0.16$ & $24.77 \pm 0.20$ & $11.74 \pm 0.18$ & $10.27 \pm 0.09$ & $3.88 \pm 0.02$ & $2.81 \pm 0.02$ & 35 \\
\hline & FF & $25.50 \pm 0.25$ & $26.00 \pm 0.31$ & $12.00 \pm 0.16$ & $10.45 \pm 0.13$ & $4.07 \pm 0.04$ & $3.00 \pm 0.05$ & 13 \\
\hline \multirow{3}{*}{$\begin{array}{l}\text { PT } \\
(0.78)\end{array}$} & UU & - & - & - & - & - & - & 一 \\
\hline & UF & $24.89 \pm 0.35$ & $25.11 \pm 0.42$ & $12.21 \pm 0.22$ & $10.53 \pm 0.22$ & $3.90 \pm 0.05$ & $2.96 \pm 0.04$ & 12 \\
\hline & $\mathrm{FF}$ & $25.46 \pm 0.16$ & $25.66 \pm 0.24$ & $12.41 \pm 0.14$ & $10.79 \pm 0.13$ & $4.16 \pm 0.03$ & $2.97 \pm 0.03$ & 21 \\
\hline RL & UU & - & - & - & - & - & - & - \\
\hline \multirow[t]{2}{*}{$(0.89)$} & UF & $26.07 \pm 0.35$ & $26.42 \pm 0.47$ & $12.74 \pm 0.10$ & $11.00 \pm 0.15$ & $4.00 \pm 0.06$ & $2.90 \pm 0.04$ & 9 \\
\hline & FF & $25.99 \pm 0.16$ & $26.25 \pm 0.25$ & $12.63 \pm 0.09$ & $10.89 \pm 0.07$ & $4.06 \pm 0.03$ & $2.95 \pm 0.02$ & 42 \\
\hline $\mathrm{P}$ & UU & - & - & - & - & - & - & - \\
\hline \multirow[t]{2}{*}{$(1.0)$} & UF & - & - & - & - & - & - & - \\
\hline & FF & $26.04 \pm 0.26$ & $25.78 \pm 0.32$ & $12.38 \pm 0.32$ & $10.91 \pm 0.16$ & $4.04 \pm 0.13$ & $3.01 \pm 0.05$ & 13 \\
\hline
\end{tabular}

TL, total length; TegL, tegmina length; FL, femur length; TibL, tibia length; PTxL, prothorax length; PTxH, prothorax height. Measurements are expressed in mm. $n=$ number of males measured.

al., 1991) and with male mating success (Norry et al., 1995). Although little is known about behaviour (let alone mating success) in $L$. argentina, there is evidence that fusion homozygotes have increased longevity (Colombo, 1993c), which, in turn, might result in an increased chance of reproductive success.

The effect on segment $s_{1}$ is more enigmatic; it is known that increased DNA contents are usually correlated with increased body size, both in plants and insects (Papeschi, 1988; Poggio \& Naranjo, 1990 ), but in this case the effect of the segment on body size was only identifiable in the populations here analysed, not in others. In any case, this is the first indication of an exophenotypic effect of a supernumerary segment and, added to its presence in all populations of $L$. argentina so far studied (Bidau \& Hasson, 1984), the nonrandomness of its distribution (Colombo, 1993b), its effects on recombination (Colombo, 1992), its gametic phase disequilibrium with fusion 3/6 (Colombo, 1993c) and now its effects on body size (this study), suggests that this segment may well not be adaptively neutral for natural populations of this species.

\section{Acknowledgements}

The author is indebted to Drs $\mathrm{M}^{\mathrm{a}}$. Isabel Remis and Viviana A. Confalonieri for critical reading of the manuscript, to the Dirección Nacional de Parques Nacionales, Argentina, for allowing the collection of grasshoppers in Parque Nacional 'El Palmar', and to two anonymous reviewers whose criticisms substantially improved the paper. Financial support through grants from the Secretaría de Ciencia y Técnica and the Universidad de Buenos Aires to Professor Dr J. H. Hunziker and Dr J. C. Vilardi is gratefully acknowledged.

\section{References}

BIDAU, C. J. AND HASSON, E. R. 1984. Population cytology of Leptysma argentina Bruner (Leptysminae: Acrididae). Genetica, 62, 161-175.

(C) The Genetical Society of Great Britain, Heredity, 79, 631-637. 
ColomBo, P. c. 1989. Chromosome polymorphisms affecting recombination and exophenotypic traits in Leptysma argentina (Orthoptera). Heredity, 62, 289-299.

COLOMBO, P. c. 1992. Effects of two supernumerary segments on intra- and interchromosome chiasma frequency in Leptysma argentina (Orthoptera). Caryologia, 45, 283-299.

COLOMBO, P. C. 1993a. A polymorphic centric fusion enhances chiasma interference in a grasshopper: a chiasma distribution approach. Heredity, 70, 254-265.

COLOMBO, P. c. 1993b. Chromosome polymorphism and natural selection in Leptysma argentina (Orthoptera). I. Correlation with geographical, climatic and temporal variables. Evol. Biol. (Bogotá), 7, 21-39.

COLOMBO, P. C. 1993c. Chromosome polymorphism and natural selection in Leptysma argentina (Orthoptera). II. Gametic phase disequilibrium and differential adult male viability. Heredity, 71, 295-299.

GROETERS, F. B. AND SHAW, D. D. 1992. Association between latitudinal variation for embryonic development time and chromosome structure in the grasshopper Caledia captiva (Orthoptera: Acrididae). Evolution, 46, 245-257.

HASSON, E., VILARDl, J. C., NAVEIRA, H., FANARA, J. J., RODRíGUEZ, C., REIG, O. AND FONTDEVILA, A 1991. The evolutionary story of Drosophila buzzatii. XVL. Fitness component analysis in an original natural population from Argentina. J. Evol. Biol., 4, 209-225.

HASSON, E., NAVEIRA, H. AND FONTDEVILA, A. 1992. The breeding sites of Argentinian cactophilic species of the Drosophila mulleri complex (subgenus Drosophilarepleta group). Rev. Chile, Hist. Nat., 65, 319-326.

ЈонN, в. 1983. The role of chromosome change in the evolution of orthopteroid insects. In: Sharma A. K. and Sharma A. M. (eds) Chromosomes in the Evolution of Eukaryotic Groups, vol. 1, pp. 1-114. CRC Press, Boca Raton, FL.

LANDE, R. 1979. Effective deme sizes during long-term evolution estimated from chromosomal rearrangement. Evolution, 33, 234-251.

NORRY, F. M., VILARDI, J. C., FANARA, J. J. AND HASSON, E.
1995. Courtship success and multivariate analysis of sexual selection on morphometric traits in Drosophila buzzatii (Diptera: Drosophilidae). J. Insect Behav., 8, 219-229.

PAPESCHI, A. G. 1988. C-banding and DNA content in three species of Belostoma (Heteroptera) with large differences in chromosome size and number. Genetica, 76, 43-51.

PARTRIDGE, L., hoffman, A. AND JONES, J. s. 1987. Male size and mating success in Drosophila melanogaster and Drosophila pseudoobscura under field conditions. Anim. Behav., 35, 468-476.

PATTERSON, J. T. AND STONE, D. 1952. Evolution in the Genus Drosophila. McMillan Publishing Co., New York.

POGGIO, L. AND NARANio, C. A. 1990. Contenido de $A D N$ y evolución en plantas superiores. Acad. Nac. Cs. Ex. Fís. Nat. (Buenos Aires), Monografía 5.

REIG, O. A., AGUILERA, M., BARROS, M. A. AND USECHE, M. 1980. Chromosomal speciation in a Rassenkreis of Venezuelan spiny rats (genus Proechimys, Rodentia, Echimyidae). Genetica, 52/53, 291-312.

Remis, M. I. 1991. Polimorfismos Cromosomicos en Acrididos Sudamericanos. Ph.D. Thesis. Universidad de Buenos Aires.

RUIZ, A., SANTOS, M., BARBADILla, A., QUESADA-DIAZ, J. E., HASSON, E. AND FONTDEVILA, A. 1991. Genetic variance for body size in a natural population of Drosophila buzzatii. Genetics, 128, 739-750.

SANTOS, M., RUIZ, A., BARBADIlla, A., QUEZADA díaz, J., HASSON, E. AND FONTDEVILA, A. 1988. The evolutionary history of Drosophila buzzatii. XVI. Larger flies mate more often in nature. Heredity, 61, 255-262.

SANTOS, M., RUIZ, A., QUEZADA Díaz, J. E., BARBADILla, A. AND FONTDEVILA, A. 1992. The evolutionary history of Drosophila buzzatii. XX. Positive phenotypic covariance between field adult fitness components and body size. $J$. Evol. Biol., 5, 403-422.

white, M. J. D. 1973. Animal Cytology and Evolution, 3rd edn. Cambridge University Press, Cambridge. 